Author has nothing to disclose with regard to commercial support.

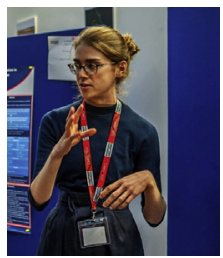

\section{CARDIOTHORACIC SURGERY EXPOSURE IN MEDICAL SCHOOL--A UNITED KINGDOM STUDENT PERSPECTIVE}

\section{To the Editor:}

I read with interest the recent article by Coyan and colleagues regarding a medical student's opinion of a career in cardiothoracic surgery at the University of Pittsburgh. ${ }^{1}$ As a current final year medical student in the United Kingdom, I recognize many of the factors identified as being barriers to initiating and maintaining interest in cardiothoracics, particularly the lack of early exposure to the specialty. In the United Kingdom, 2 cardiothoracic training pathways exist -a 6-year program after 2 years of core surgical training and, as of 2013, an 8-year specialty "run-through" program. ${ }^{2}$ A move toward earlier specialization, as well as recent difficulties identified in trainee recruitment, ${ }^{3}$ indicates a need for early exposure to not only stimulate interest and provide career insight, but to obtain experience necessary for an informed application to a competitive process.

I certainly agree that initial stimulation of interest, which has previously been identified as an issue in the United Kingdom, ${ }^{4}$ is a key problem. With two-thirds of students surveyed expressing interest in a particular specialty, it is clear that students are proactively making early career pathway decisions, but only one-third consider cardiothoracics. I find this somewhat unsurprising because of the lack of exposure that students receive. Although it is understandable that general surgical rotations should form most of the surgical teaching in the core curriculum, cardiothoracic surgery is not routinely taught. In my own medical school experience, optional exposure is limited to a 4-week student-selected elective module in the penultimate year, whereas other specialist surgical subspecialties such as breast, vascular, and neurosurgery might be experienced by students in their first clinical

\footnotetext{
The Editor welcomes submissions for possible publication in the Letters to the Editor section that consist of commentary on an article published in the Journal or other relevant issues. Authors should: • Include no more than 500 words of text, three authors, and five references. $\bullet$ Type with double-spacing. • See http://jtcs.ctsnetjournals.org/ misc/ifora.shtml for detailed submission instructions. • Submit the letter electronically via jtcvs.editorialmanager.com. Letters commenting on an article published in the JTCVS will be considered if they are received within 6 weeks of the time the article was published. Authors of the article being commented on will be given an opportunity of offer a timely response ( 2 weeks) to the letter. Authors of letters will be notified that the letter has been received. Unpublished letters cannot be returned.
}

year. In addition, many students elect for broader specialties that are more likely to be assessed in final exams at this late stage, rather than trying out a new specialty for their elective module. I fully agree that early "mini-electives" in preclinical/early clinical years would certainly be helpful, and indeed in the United Kingdom cardiothoracic engagement days run for sixth form and medical students aim to initiate interest early on.

I think early stimulation of interest must be made alongside efforts to maintain interest, if we are to challenge developing negative perceptions of cardiothoracic careers. It also seems wise that the paradoxical correlation between negative perception and lack of exposure should prompt investigation into where students are obtaining information. Preece and colleagues have previously identified a lack of cardiothoracic engagement in curricular and extracurricular activity as a reason why interest is not maintained..$^{5}$ In the United Kingdom, various schemes support interested students with cardiothoracic specialty application. The Society for Cardiothoracic Surgery actively pairs cardiothoracic teams and students through involvement in audit data collection, and the Royal College of Surgeons Edinburgh offers 3-week student placements in cardiothoracic centers. "Sugar-coating" the intensity of cardiothoracic training to tackle work-life balance concerns is decidedly not a solution, but following-up early exposure with further opportunities and long-term mentorship seems essential to providing realistic insight for interested students as they develop over the course of medical school.

\section{Beth Taylor, BSc Imperial College School of Medicine Imperial College London, United Kingdom}

\section{References}

1. Coyan GN, Kilic A, Gleason TG, Schuchert MJ, Luketich JD, Okusanya O, et al. Medical student perceptions of a career in cardiothoracic surgery: results of an institutional survey. J Thorac Cardiovasc Surg. August 27, 2019 [Epub ahead of print].

2. NHS Health Careers. Training and development (cardiothoracic surgery). 2020 Available at: https://www.healthcareers.nhs.uk/sites/default/files/documents/ Surgical_Training\%20Pathway\%20updated.pdf. Accessed August 17, 2019

3. Westaby S, Baig K, De Silva R, Unsworth-White J, Pepper J. Recruitment to UK cardiothoracic surgery in the era of public outcome reporting. Eur J Cardiothorac Surg. 2015;47:679-83

4. Gasparini M, Jayakumar S, Nardini MN, Dunning JD. Medical student exposure to cardiothoracic surgery in the United Kingdom. Interact Cardiovasc Thorac Surg. 2019;29:173-8.

5. Preece R, Ben-David E, Rasul S, Yatham S. Are we losing future talent? A nationa survey of UK medical student interest and perceptions of cardiothoracic surgery. Interact Cardiovasc Thorac Surg. 2018;27:525-9.

https://doi.org/10.1016/j.jtcvs.2019.08.093 